\section{Incarnation, Timelessness, and Leibniz's Law Problems}

THOMAS D. SENOR

The Issue at Hand

According to classical Christian theology, God exists atemporally. Orthodox Christology insists that Jesus Christ is numerically identical with God the Son, the Second Person of the Trinity. This identity statement, however, when taken in conjunction with other claims a traditional Christian wants to make, can be seen to provide a prima facie powerful argument against the doctrine of atemporality. Stated very briefly, the argument runs like this:

1. Jesus Christ was the bearer of temporal properties.

2. No bearer of temporal properties is atemporal.

3. Jesus Christ $=$ God the Son (a divine person).

4. God the Son is not atemporal.

Now Christian theology does not want to identify one member of the Trinity with any other, much less with them all. So the atemporality of the Godhead does not obviously follow from (4). It does follow, however, that there exists a temporal divine being and, a fortiori, atemporality is not essential for divinity; each of these consequences would be resisted by the standard defender of divine timelessness.

It rarely behooves one to be too dogmatic in asserting theological conclusions, so I conclude only that the above argument is prima facie sound and that it provides the theological temporalist with the upper hand in his dispute with the atemporalist.

My purpose in this essay is not to rehash an argument that $I$ have presented more fully elsewhere. ${ }^{1}$ Rather, I am interested in defending an argument like that above from an objection that I have heard voiced by the three most able defenders of atemporalism, viz., Eleonore Stump, Norman Kretzmann, and Brian Leftow.
The reply to the argument that the Incarnation rules out timelessness that will concern us runs as follows: well, sure, you can generate a problem with combining atem porality and incarnation, but why is that at all interesting? Everyone knows that there is a whole set of such so-called Leibniz's Law problems. These logical difficulties are generated as follows: since Jesus Christ is fully human, and property $P$ is essential to humanity, he exemplifies property P. So if he is identical to God the Son, then according to Leibniz's Law, the latter must exemplify $P$, too; but necessarily, no divine being can exemplify $P$, so the identity claim must be false. For the property-term-placeholder P, one may substitute "being limited in knowledge," "being limited in power," "being morally corruptible," "existing contingently," etc. Now, to be sure, one problem instance involves the attribute of temporality; but so what? If you are a Christian who also believes in the Law of Noncontradiction, then you had better believe that there is a way of working out such problems; and if you find a solution for all of these other Leibniz's Law difficulties, you will find one for the temporality/atemporality problem, too. So there is no better reason for thinking that the Incarnation shows that the Son is temporal than there is for thinking that it shows that the Son is limited in knowledge and power. ${ }^{2}$

It is this objection that I want to examine critically in this essay. I hope to show that, the above line of reasoning notwithstanding, the doctrine of the Incarnation does pose a special, if not unique, problem for the doctrine of timelessness.

\section{A Preliminary Distinction}

In order to show that the doctrine of timelessness raises particularly thorny problems with respect to the Incarnation, I will have to distinguish two kinds of properties. I begin by marking this dichotomy.

The distinction that $I$ have in mind is epistemological rather than metaphysical. That is, it divides properties according to the access that we have to their instances rather than according to their essences. First, consider what I will call an "observable property." As one might think, this is a property that one can come to know to be exemplified by an object just in virtue of observing that object. Hence, color, relative size (within rather generous parameters), shape, texture, etc., are examples of such properties. Now of course, I am being far too simplistic here, at least far too simplistic for certain purposes. For there is a fact about the current color and texture of my heart but, fortunately for me, that is not an observable property at this time. However, I propose not to bother tidying up this very loose notion of observable property. For while I acknowledge that it is quite rough, it is adequate for our purposes. ${ }^{3}$

As one might expect, I wish to contrast observable properties with "unobservable properties." An unobservable property is a property the exemplification of which cannot be known by simple observation. Clear examples of such properties are being combustible, being well liked by the president, and being the sort of organism brought about by random genetic mutation. Since my characterization of observable properties is loose, my description of unobservable properties is as well. One point to note however, is that whether a property is observable or unobservable is relative to the attributes of the cognizer or the class of cognizers and to the conditions of observation. 
The color of medium-sized physical objects is, in the right circumstances, an observable property of that object if one is a human being with a properly functioning visual system. However, to those who lack such a system, color might well be an unobservable property. It will make matters more manageable if I do not always have to acknowledge explicitly the cognizer and context relativity of this distinction; so unless I say otherwise, assume that the class of cognizers is that of properly functioning human beings, and that the conditions of observation are optimal for observing the property in question.

\section{Why Ours Is Not Simply Another Leibniz's Law Problem}

Armed with this distinction, let's return to our primary problem. Orthodox Christology demands that we identify Jesus of Nazareth with God the Son, the Second Person of the Trinity. But which properties are we constrained by orthodoxy to impute to the Incarnate God? Well, clearly if he is to be God we shall have to ascribe to him all of those properties that are kind-essential for divinity. So, inter alia, we shall have to say that he is omnipotent, Creator of all that exists other than himself, and omnibenevolent; I assume that no being who lacks these properties can count as divine. ${ }^{4}$ And we must also ascribe to him those properties which are kind-essential for humanity. Which properties are those? That is rather hard to say. Thomas Morris and Richard Swinburne have argued that it is not at all clear in precisely what the human kindessence consists. ${ }^{5}$ If we knew the essence of humanity, the job of checking for the logical consistency of the doctrine of the Incarnation would be straightforward. But since there is no known univocal answer to what is essential for being human, things are anything but simple.

Nevertheless we are not completely at a loss on this issue. Although it is, perhaps, easier to see what is not a part of the human kind essence rather than what is: it may or may not be necessarily true that each human is embodied at every moment that he or she exists; however, no one would seriously maintain that being disembodied is essential for humanity. Even if, necessarily, humans have stages during which we are disembodied, being disembodied (i.e., at every moment of one's existence) is not a part of the human kind-essence. Similarly, even the Christian who accepts the doctrine of total depravity will not claim that being totally depraved is essential for being human. For this would preclude the logical possibility of an individual's ceasing to be sinful and with it the Christian commitment to the eventual completion of the sanctification process. ${ }^{6}$ Indeed, the example of total depravity illustrates a key point: a property may be extremely common without being essential.

Furthermore, our ignorance does not preclude our ascribing certain particular human properties to Christ. Because he was in many respects a rather ordinary man, there are a whole host of properties that he shared with his fellow first-century Jews; so we must ascribe to him those accidental features of the time and place of the Incarnation. The Gospels are another source of data concerning Christ's human properties. One need not think that a Christian has to hold that Jesus did everything that he is portrayed as doing in the Scriptures; but surely the traditional believer will take seriously the account of Christ in the Gospels and reject only that which there is strong reason to reject.
Now among those properties that Christ exemplifies, some will be observable and some will be unobservable. Presumably, his divine attributes will fall into the second classification. Peter, for example, could not just look at Jesus and observe that he was the omnipotent Ground of All Being. However, many of the accidental features of Jesus would have been observable. For example, Peter could see that Jesus had dark hair, that he wore a robe and sandals, and that he broke bread with his hands. In fact, there are properties that are clearly not kind-essential for humanity but that we can nevertheless be sure that Jesus had. The most obvious of these are that Jesus had a body with certain particular characteristics, that his primary mode of transportation was walking, and that there was a particular temporal ordering to what he did. Any of Christ's properties that was observable to the disciples is surely a property that we must be willing to ascribe to him.

Now when we add these observable properties to the divine properties, we get a pretty robust description of God Incarnate. He is a male human being who was physically very much like other men of his time and place, who nevertheless was the omnibenevolent, omnipotent Creator of all that is other than himself. We have here what appears to be a coherent description; at least it involves no obvious contradiction. However, if we add other attributes that are sometimes thought kind-essential for humanity, things change rather quickly. For example, if we think that every human must be limited in power and morally fallible, and we thus add this to our description of Christ, the inconsistency of the resulting description is overdetermined. However, as Morris and Swinburne have pointed out, it is hard to see why a Christian should feel constrained to make these claims about the human kind-essence. Surely a normal or typical human is limited in power and knowledge, but that is not an indefeasible reason to think it necessary that nothing could be human without being so limited.

At this point one might worry that the view thus far sketched would allow that every human being is only accidentally not divine. That is, if the human kind essence does not preclude omnipotence or any other divine-kind attributes, then it might look as though we may each be possibly divine, that for each of us there is a possible world in which we are God. But surely that is too much to swallow and completely contrary to what Christianity teaches about human beings. Fortunately, the view I am interested in defending is not saddled with this consequence. In addition to our human natures or kind-essences, we each also have individual essences. Our kind-essences are shared by all humans, but our individual essences are unique. A property is a part of the individual essence of a being if that being could not continue to exist if it ceased to have that property. One's individual essence is the set of all such properties for the given individual. Thus, one can insist both that there is no inconsistency in claiming that some being might have all the kind-essential attributes of divinity and humanity while at the same time denying that every individual who is a human is only contingently so. For it could be that the standard human's individual essence includes his or her being created and limited in power and wisdom. So one who defends the coherence of the Incarnation has only to claim that, possibly, there is an individual who is human (i.e., who instantiates the human kind-essence) and whose individual nature contains the kind-essential properties of divinity.

Let's return to the main lines of argument: the point here is that once we recognize that it is not obvious that limits to power and goodness are a part of the human kind- 
essence, then we can see that there is substantial room to maneuver in face of the standard Leibniz's Law problems. One has those difficulties only if one already accepts a robust philosophical anthropology that there is no particularly good reason to adopt. The Christian only has a serious problem if there is a clash between a human property that one is compelled to ascribe to Christ and a kind-essential property of divinity. If that happens, one is in a serious Christological bind.

Now from what we know about Jesus in the Gospels, it is clear that he had the observable properties listed above (i.e., he had a body with certain particular features, walking was his primary mode of transportation, and he did certain things before he did others, etc.); these properties can be ascribed to Christ without making any important anthropological assumptions other than that he was human. Were we to have had the good fortune of being original disciples, we could simply "read off" such properties from Christ's physical appearance and his actions. And as we have seen, these properties are consistent with the properties of divinity that we have been considering. But what if we add to the list of kind-essential properties for divinity "atemporality"? Now we get a description of a person with a human body whose actions (both the acts and their consequences) are temporally ordered but who is nevertheless timeless. I say "both the acts and their consequences" because the Scriptures portray Jesus Christ as not simply a person who brings about effects that are in time, but as a person who is in time; so if we add atemporality to this portrait, we get a sketch that no one could possibly satisfy. Therefore, I contend that this account of the Incarnation is incoherent

The general point, then, can be put as follows: unless you begin your Christological investigation with a certain, rather strong philosophical anthropology, there is no good reason to think that there are irresolvable Leibniz's Law problems concerning such divine kind-essential properties as omnipotence, necessary existence, and omnibenevolence. None of these properties is obviously inconsistent with one's being human since none of them entails the denial of any observable human property. However, were timelessness thought to be kind-essential for divinity, things would be rather different. For traditional Christology insists that Christ had a body of flesh and blood. But every embodied human exemplifies observable, temporal properties. So if Christ is embodied, he exemplifies observable, temporal properties; and if he has such properties he is not timeless. So if one insists that atemporality is necessary for divinity, it will be very hard to assert that Christ was divine without committing oneself to a contradiction. And once again the key point is that one can generate such a contradiction without making any significant anthropological claims whatsoever.

\section{An Objection}

We must now consider a very important objection that would seem to seriously undermine the argument of this essay. Altiough superficially this appears to be two, mostly unrelated, problems we will be able to see presently that there is a uniting thread. Here is the problem: okay, so your position is not completely without merit. Certain of the kind-essential features of divinity (e.g., omnipotence, omnibenevolence, and necessary existence) are consistent with Christ's observable properties; and atemporality would seem not to share this desirable trait. However, you have spoken as though this problem is unique to timelessness. But it is not. Surely, e.g., incorporeality is kindessential for divinity, but it is also apparently inconsistent with the observable properties of Christ. So your main thesis, i.e., that timelessness is in conflict with the Incarnation in a way all other attributes are not, is mistaken. ${ }^{7}$ Besides, the situation is not nearly as bad as you make it sound. For there is a long tradition that recognizes that the attributes of deity are had by Jesus Christ qua divinity while the typical observable properties are had qua humanity. Now to be sure, more needs to be said about this; but here we have the seeds of a reply to all Leibniz's Law objections.

There are two discernible parts to this objection. The first is aimed at my claim that the Incarnation poses a special problem for the doctrine of timelessness. It is alleged that even if the Morris/Swinburne line defuses the problem for many of the divine properties, there are others that are recalcitrant; i.e., there are observable properties of Christ that are apparently inconsistent with characteristics traditionally attributed to God. So my claim that the timelessness problem is unique is incorrect.

The second part of the above objection is more general. The claim is that I have exaggerated how bad these Leibniz's Law problems are and that we do have a good idea of how to go about solving them; apparently inconsistent properties can be had by Christ so long as they are attributed to him qua different natures. So Christ qua God is omnipotent but Christ qua human is not. This move (call it the "qua-move"), perhaps with a few added bells and whistles, will solve all the traditional Leibniz's Law problems. So there is no special worry regarding atemporality.

Let's take these problems in turn.

\section{On the Uniqueness of the Atemporality Problem}

It is clear that there is something right and important about this objection. There are other attributes that would seem to follow from the observable properties of Christ that, prima facie, cause problems for the traditional understanding of the Incarnation.

How serious this objection is will depend on two things: the number of allegedly divine kind-essential properties that are inconsistent with Christ's observable properties and the significance of those properties. If there is massive conflict or if the conflict is with what we might call "core" (alleged) divine properties, then we shall have to hope for some solution to the Leibniz's Law problems that is radically different from the Morris/Swinburne line sketched above. However, if the number of apparently inconsistent properties is small and if, for each troublesome pair, either the alleged divine or alleged human property is sufficiently negotiable (i.e., not central), then the Morris/Swinburne line looks promising indeed and the above objection to the argument for the temporality of God based on the Incarnation is not troubling.

One final prefatory note. One who adopts the Morris/Swinburne line and gives up atemporality (and perhaps other allegedly divine properties) will be bucking a certain tradition, there are no two ways about it. There are deep and important issues of philosophical and theological methodology here that we will discuss briefly later in the essay.

Which alleged divine properties seem to directly conflict with observable properties of Christ? Incorporeality is an example. Christ's having a body means that he has 
an observable property (i.e., being embodied) that is inconsistent with the doctrine of incorporeality (and with that of aspatiality as well). Are there other attributes normally ascribed to God by traditional theology that are inconsistent with observable properties?

One might think that Christ's being born of Mary (a property he was observed to have by at least Mary) is inconsistent with his being necessarily existent or even preexistent. As plausible as this sounds, I believe it can reasonably be resisted. For in order for this to be a worrisome pair of properties, there would have to be a fairly direct logical relation between "being born" and not existing necessarily or being preexistent. Now if " $\mathrm{X}$ is born at $t$ " implied that "X did not exist prior to $t$," then we would have a real problem. But of course the former does not imply the latter. Not only is there not a relation of logical necessity between the two, but most of the true substitution instances of the first are cases in which the appropriate substitution instances of the second are false. Surely the being who leaves the birth canal at $t$ existed in the canal at $t_{-1}{ }^{8}$

Are there other attributes, traditionally ascribed to God, that conflict with the observable properties of Christ? Perhaps, but I fail to see what they are. What we are looking for here are properties (or their immediate logical consequences) that were directly observable by any first-century resident of Palestine. Being embodied implies being "in" space and time, but from what I can see not much else.

There is a second sort of problem case that might be thought relevant here. Jesus is often portrayed in the Gospels as showing standard human emotions (e.g., sorrow and anger). Having these emotions is inconsistent with the attribute of impassibility, so that would seem to be another attribute in jeopardy. ${ }^{9}$ Similarly, Jesus claimed that only the Father knows the date of the Second Coming, which in the context of his utterance strongly suggests that Christ took himself to lack such knowledge. These sorts of difficulties might be classified as conflicts between observable properties and traditional divine properties, because while the complements of the divine properties are not entailed by observable properties the latter nevertheless provide relatively direct warrant or justification for the attribution of properties inconsistent with the properties of impassibility and omniscience. For example, Christ's having the property of wearing a facial expression generally associated with anger while overturning tables and casting the money changers out of the Temple is pretty good prima facie evidence of genuine anger; still, it is by no means conclusive. These facial and behavioral properties do not entail anger. Similarly, Christ's apparent claim of ignorance regarding the timing of the Second Coming does not entail a lack of omniscience, although it might be seen as pretty good evidence for it. ${ }^{10}$

Problems of this second sort are, perhaps, more in number but are almost certainly less in impact. For they provide only prima facie evidence of incompatibility; the philosophical theologian has options for defeating the alleged incompatibility. These options range from reinterpreting the troublesome biblical passages, to denying their accuracy, to giving alternative accounts of the divine properties in question (e.g., one can claim that omniscience does not require constant access to the information contained in the omniscient mind, and one can take a behaviorist view of the divine mental life in order to save impassibility as, e.g., Anselm does). Now back to the more straightforward problem concerning incorporeality and impassibility. Does my position force me to accept the corporeality and passibility of Christ? Yes, I believe so Does that mean I must accept the corporeality and passibility of God? Well, yes and no. Inasmuch as I accept the truth of the Incarnational identity claim "Jesus Christ is God the Son" as well as the corporeality and passibility of Christ, I must accept the corporeality and passibility of God the Son. That does not mean, however, I must accept the corporeality and passibility of the Godhead (i.e., of the Trinity), and still less that I must accept that the Father or Spirit is corporeal and passable.

If I do accept that Christ was divine and yet corporeal and passable, then I must accept that incorporeality and impassibility are not kind-essential for divinity. As I mentioned above, this is not to affirm that either the Father or the Spirit is corporeal or passable. Further, it is instructive to see that one can hold all of the above and still maintain that the Godhead is naturally incorporeal and impassable, i.e., that incorporeality and impassibility are what I have elsewhere called "ceteris paribus" properties of divinity. ${ }^{1 /} \mathrm{P}$ is ceteris paribus property for kind $k$ if and only if property instances of $k$ will have $\mathrm{P}$ if other things are equal, or in normal or standard circumstances. So, e.g., water has the ceteris paribus property of boiling at 212 degrees Fahrenheit. However, if water has salt added or is being heated at a high altitude, or if the laws of nature were different in certain ways, then this property is not exemplified. So while water has the property of boiling at 212 degrees F. naturally, as it were, it does not have this property essentially (although it does have the ceteris paribus property essentially).

The traditional Christian who holds both the corporeality and passibility of Jesus Christ and hence of God the Son (at least during his earthly ministry) can nevertheless maintain that a divine being is "naturally" (though not essentially) incorporeal and impassable. It is only when a divine Person takes on a second nature or in some other way alters himself that incorporeality and impassibility are set aside. ${ }^{12}$ The account of divinity is unchanged except that what is essential for being divine are not, say, the properties of simple omniscience, incorporeality, etc., but is instead the second order property of having the ceteris paribus properties of omniscience, incorporeality, etc. But if we make this move, one might think: do we not in the end really give up the whole idea of the divine nature? Does it not risk making the notion of "a nature" so malleable as to be no longer profitable to discuss? I think not. For the kind-nature that an entity exemplifies will (partially) determine its ceteris paribus properties. It is because water has the essential properties that it does that it has the ceteris paribus property of boiling at 212 degrees F. Similarly, it is because of the essence of divinity that any divine being will have the ceteris paribus property of omniscience. This way of construing the divine kind-nature makes divinity more closely analogous with kindnatures in general. If we think the essential properties of divinity are omniscience, omnipotence, omnibenevolence, and the like, and that the way we know this is via a priori reflection on the concept of God, then we are seeing the concept of God as much more like a "cluster concept" (like, e.g., bachelor) than like a natural (or supernatural) kind-concept. If we see divinity as closely analogous to a natural kind, then we shall think there is a fundamental divine nature not knowable a priori-or at least not by simple reflection on the concept of divinity. Of course, it is perfectly consistent with everything said here that God may choose to reveal himself to us and that we shall 
learn certain of his important properties that way. Even if they turn out not to be technically essential for divinity, that God is ceteris paribus omniscient and incorporeal can be important truths for God to reveal to his followers.

In this discussion I have heretofore avoided the question of whether the traditional Christian should hold that divinity includes the properties of impassibility and incorporeality. There is a broad theological tradition, however, even within Christological orthodoxy, that maintains that impassibility should be jettisoned. This is not the place to thrash about in these deep and often turbulent theological waters. For our purposes it is sufficient that we note that these matters are of great controversy and that even many who accept the two-natures view of the Incarnation are not inclined to accept the complete traditional package.

Despite my position that there are ways the friend of divine temporality can mitigate the damage of the objection we have been considering, I want nevertheless to acknowledge that it raises key issues in Christian philosophical theology. The primary issue it brings to light centers on the implications of the Incarnation: to what extent should a Christian allow her Christology to influence her theology? That is, is it theologically permissible to let what she believes about Jesus inform what she believes about God? It is clear, I suppose, that one can go either too far or not far enough on this score. For instance, one who said that Christ's distaste for empty piety did not reflect God's attitude would clearly be denying an important revelation. On the other hand, if I claim that because Jesus wore sandals, God prefers that we all do, I would not deserve to be taken seriously. So we can all agree that while God might be most fully revealed in the life and person of Jesus Christ, there are limits to reading the mind and nature of God from the preferences and actions of Jesus.

But there will be important points of disagreement, too. For example, I am inclined to take the Gospels' portrait of Christ to reveal the depth to which God has compassion for humanity; and by "compassion" I do not mean to say, as does Anselm, only that God acts in compassionate ways. I also intend to assert that God has some analogue of the human emotional state of compassion. But to accept this is to reject the traditional doctrine of impassibility. Now one fully persuaded of the classical picture in its entirety will insist that the Gospels can be consistently read behavioristically. Or perhaps she will say that the compassion and suffering of Christ are to be predicated "qua humanity" only. This then leads us to the second part of the above objection. The objector's second claim is that as long as, e.g., incorporeality or impassibility is had qua divinity and its logically complementary property is had qua humanity, then the person identified as Jesus Christ and God the Son (for simplicity's sake, we will hereafter refer to him as the Redeemer) can consistently possess them both

The defender of the qua-move is claiming that the traditional divine properties are held by the Redeemer only qua God. But precisely what is it that is being claimed? It seems that there are three ways of spelling out the details of the qua-move, i.e., of what are known as redupiicative sentences. In the next section, I will have a look at cach of these three possibilities and argue that two of them simply cannot do the job of avoiding the Leibniz's Law problems that motivate their adoption. The third is apparently able to solve such problems, but adopting it requires accepting an account of properties that is motivated solely by the desire to avoid Leibniz's Law problems and as such is simply an ad hoc adjustment that creates as many problems as it solves.
The Three Ways

Although the qua-move is somewhat familiar, let's take a moment to rehearse it. Suppose someone claims that Christian theology is logically inconsistent because it asserts or entails

A. Jesus Christ was omnipotent

and

B. Jesus Christ was not omnipotent.

The friend of the qua-move will say that both $A$ and $B$ are ambiguous and that the only readings of them that the orthodox believer is committed to are expressed by the following reduplicative sentences (i.e., sentences that ascribe a property qua God or qua humanity):

A*. Qua God, Jesus Christ was omnipotent.

B*. Qua human, Jesus Christ was not omnipotent. ${ }^{13}$

Unlike A and B, the propositions expressed by $A^{*}$ and $B^{*}$ are not straightforwardly inconsistent. So, apparently, the qua-move works to dispel the prima facie contradictions in traditional Christology.

Things are not so clear-cut, however. While it is plain that $A^{*}$ and $B^{*}$ are not explicitly inconsistent, it is by no means obvious how they are to be understood and whether there is a way of understanding them that will do the job of undercutting claims of logical inconsistency. There are, I believe, three ways that one might understand reduplicative sentences. The first, and most straightforward, reading is "In virtue of being N, S is F." Thus, understood this way, if one says, "Qua God, Jesus Christ was omnipotent," one is saying that it is in virtue of his deity (or his divine nature) that Christ was omnipotent. This interpretation has the twofold advantage of being clear and intuitive in addition to being uncontroversial within the Christian tradition. Everyone will say that Christ has his divine properties in virtue of his divine nature and his human properties in virtue of his human nature.

The difficulty with this interpretation of qua-sentences for the purpose of solving Leibniz's Law problems is that it does not solve them, for the "F-entailment" still goes through. This is easy to see: sentences of the form "In virtue of N, S is F" entail sentences of the form " $S$ is F." So "In virtue of being divine, Christ is omnipotent" entails "Christ is omnipotent"; and "In virtue of being human, Christ is not omnipotent" entails "Christ is not omnipotent." We are right back where we started. Hence, understanding reduplicative settences like this will not help defend orthodoxy because in the end we will still be left with simpliciter properties and the contradictions they promote.

A second way of understanding reduplicative sentences is to take the qua-clause to be imbedded in the grammatical subject of the sentence. We can make this clear by appropriately placing hyphens. "Qua N, S is F" becomes " $\mathrm{S}-q u a-N$ is F." Applying this 
to our example, we get "Christ-qua-God is omnipotent" and "Christ-qua-human is no omnipotent." The properties of omnipotence and non-omnipotence are predicated simpliciter, but contradiction is avoided because the properties are predicated of different subjects, i.e., of Christ-qua-God and Christ-qua-human. So while it is true that the relevant property is attributed simpliciter, this interpretation of qua-sentences stil manages to block the inference from "Qua N, S is F" to "S is F," because the subjects are not identical.

Herein lies the difficulty. If one is to claim that in the Incarnation there are two subjects of predication one will be in effect adopting the heresy of Nestorianism.For this interpretation avoids the logical problems of the Incarnation by predicating the in compossible properties of different subjects. It is not the single person, the Redeemer who bears these properties, but rather the divine nature bears the divine properties and the human nature bears the human properties. So the bearers of the divine and human properties are at best the two respective natures; this is Nestorianism pure and simple.

I will discuss one final way of interpreting reduplicative sentences and hence the qua-move; this "third way" has the considerable virtue of avoiding each of the pitfalls that do in the other possibilities. On this rendering, "Qua N, S is F" is to be understood as " $\mathrm{S}$ is F-qua-N." That is, the qua-clause gets packed into the predication in such a way as to form a single, non-compositional, simple property. The F-entailment is blocked here because the properties being ascribed bear no non-trivial logical relation to each other. The problem with the first reading was that the properties being ascribed were logical complements; this fact was thinly masked by the fact the ascriptions were made to the subject via the respective natures. In contrast, the properties "incorporealqua-God" and "corporeal-qua-human" are, despite appearances, non-composite properties that are not logically complementary. Hence, the F-entailment is blocked. And because reference to the natures is embedded in the property being ascribed rather than in the subject, there is a single subject of predication, and so Nestorianism is avoided.

Looked at slightly more technically, the proposal we are considering is the following: the Redeemer has at least two very distinct sets of properties, each set consisting of members that are ordered pairs. The first member of each pair in one set is divinity; the second member of each pair is some particular divine property (e.g., omnipotence). In the second set, the first member of each ordered pair is humanity (or human nature), and the second member is some quality necessarily exemplified by anything that has that nature. 14

So far, so good. However, this view also generates serious problems. Recall that it is not sufficient that the Redeemer have the relevant hyphenated property and that that property fail to entail the relevant simpliciter property, i.e., that the F-entailment is blocked; it must also be the case that the Redeemer not have either the divine or the human property simpliciter. That is, suppose that "qua-subtraction" is a bad inference rule and that the way to understand reduplicative sentences is as the third way sug gests. It does not follow from this that the problem is solved. For even if we accept that the Redeemer has the encapsulated properties of, e.g., omnipotent-qua-God and limited-in-power-qua-human, there is still the question of whether he has the property of omnipotence simpliciter. If he does (presumably because of his divinity), then we shall also need to know if his humanity requires that he is limited in power. If the an- swer to both is affirmative, then we are right back where we started. On the other hand, if the answer to one (either one) is yes and the answer to the other is no, then we have no need of the qua-move after all since we are not, even prima facie, attributing incompossible properties to the Redeemer

Therefore, the third way on its own accomplishes nothing. In order for the third rendering of reduplicative sentences to provide a solution to these Leibniz's Law problems, it shall have to block any ascription of the traditional attributes to the Redeemer; furthermore, it shall have to block the limitation properties typically thought to be essential to humanity. What this comes down to, I believe, is that if it is to be helpful at all, the third way shall have to be accompanied by a denial of a version of the Law of the Excluded Middle.The particular version of this law that is relevant here says that for every property and every object, either that object has that property or it lacks it.

So my claim is that for the third reading to reduplicative sentences to be potentially helpful in solving Leibniz's Law problems, its proponent will have to ensure that neither the simpliciter divine properties nor the simpliciter limitation properties are ascribed to the Redeemer. Perhaps the most natural way to do this is to deny the Law of the Excluded Middle for properties. For suppose it is not false: then no matter how we interpret the reduplicative sentences, it must be that either the Redeemer has the property of, say, omnipotence or he lacks it. Now we have been assuming the Law of Noncontradiction for properties, so it will follow that the "or" is exclusive. Similarly, he will either have or lack the human limitation properties. If he has both omnipotence and the limitation properties, we are back where we started. But if he lacks omnipotence, then it is impossible for him to be God. And if he is omnipotent and lacks human limitations regarding power, then we have our original questions about his humanity. ${ }^{15}$ So the friends of the third way will have to supplement their reading of reduplicative sentences in order for it to even begin to help with Leibniz's Law problems. One such supplement is the denial of the Law of the Excluded Middle for properties.

There is, however, one way of attempting to save the third rendering and its potential ability to solve the Leibniz's Law problems without denying the Law of the Excluded Middle for properties. One might claim that there just are no such properties as omnipotence simpliciter, omniscience simpliciter, and all the rest. Nominalism about the traditional divine properties would eliminate the need for denying the relevant version of the Law of the Excluded Middle, there being no such properties to begin with.

Is there any way of motivating divine property nominalism that is not hopelessly ad hoc? Maybe. Perhaps each of the divine properties is so completely embedded in the divine essence that it is necessarily, indissolubly related to it. Such a view might be thought to have attractive theological implications. First and most obviously, it would seem to provide a certain kind of unity to the divine nature. Rather than thinking of divinity as a collection of otherwise diverse properties, this proposal has omnipotence, omniscience, and the like as inseparably united with the divine nature and as not logically capable of instantiation apart from it. Secondly, it is also thought to be theologi cally odious to think of the "omni" properties as possibly instantiated by any being but that than which none greater is possible, i.e., God. Now strictly speaking, one can consistently hold that, e.g., omnipotence simpliciter is both a genuine property and yot is 
such that, necessarily, it can be instantiated only by God. However, if there is no such simpliciter property, if God's power is so entangled in the divine nature as to be inseparable from it, then there simply, and obviously, is no possibility of there existing a non-divine omnipotent being. Finally, the proponent of divine property nominalism can refer to the distinction between concepts and properties as a means of adding some plausibility to her position. She can claim that although we do have concepts of omnipotence, omniscience, omnibenevolence, and all the rest that seem to be (or indeed "are") conceptually independent of divinity, that does not tend to show that there are properties that are metaphysically independent of divinity.

We have distinguished two versions of the third way: one adds a denial of the Law of the Excluded Middle to the hyphenated, non-compositional property understanding of the qua-move; the other adds nominalism regarding traditionally understood theological properties. For the purpose of evaluating their ability to solve Leibniz's Law problems, however, we can treat them as one, since they have in common their reading of reduplicative sentences and their denial of simpliciter properties' application to God.

Despite its initial attractiveness, however, the third way brings with it its own set of problems. First, it requires a change in the way the divine nature is frequently construed. It has become common to cash out the divine nature by reference to the "omniproperties." Thus, to be divine is to be omnipotent, omniscient, omnibenevolent, and the like. ${ }^{16}$ Now the natural way to understand this proposal regarding the divine nature has these properties as simpliciter properties. However, if that is right, then the Redeemer (and each other member of the Trinity) will fail to be divine, since he will lack simple omnipotence.

There is an obvious way of trying to avoid these charges. One might take these considerations to show that our account of divinity needs to be altered. Rather than requiring, say, omniscience for divinity, one should require omniscience-qua-God This is a property that the Redeemer (and the other members of the Trinity, one would suppose) has on the present proposal. But to think that this alteration fixes things is to misunderstand the matter, for the resultant account is blatantly circular. For we have an account of the nature of God that consists of the properties of omnipotence-quaGod, omniscience-qua-God, etc. Having the properties necessary and sufficient for divinity make reference to "God" is to render the account viciously circular. A second problem with this solution is that even if it manages to avoid paradigm-case Leibniz's Law problems, there are other parallel problems that it does not address at all. For example, as we are understanding it now, the qua-move asserts that the Incarnation does not involve attributing contradictory properties to an individual, because the property of, say, being omnipotent-qua-God is a simple property which does not include the property of being omnipotent. So we can consistently say of the Redeemer that he was omnipotent in his divine nature and not omnipotent in his human nature, since it does not follow from these attributions that he had the property of omnipotence and lacked the property of omnipotence. The third way claims that this entailment is blocked because either the Law of the Excluded Middle for properties does not apply or there is no such property as simple omnipotence. So the Redeemer has the property of being omnipotent-qua-God. What does his humanity require? One possibility is that it requires that he have the property of being only-finitely-powerful-qua-human- ity, where this property too is encapsulated, and so the inference that the Redeemer is only finitely powerful is blocked. This is, I think, the best that the defender of third way could hope for

So what is the parallel problem that I alluded to in the above paragraph? Take any action that is clearly out of the range of standard human powers but would seem clearly performable by a divine being. Suppose the action is parting the Red Sea. Now we can ask whether or not the Redeemer can perform that action, whether he has the ability to do such a thing. If he can perform it, then his range of powers is clearly not within the standard range of human powers. And even if he possesses the insulated property of being limited-in-power-qua-humanity, the fact is that there are not the limitations on the Redeemer's actions that there are on the rest of us-at least, whatever limitations there might be are not nearly as severe as the limitations on us. Then again, if we say that he cannot perform the action, then it would seem that his range of action falls short of that required for divinity even if he has the hyphenated property of omnipotence-qua-divinity.

The point here can be expanded beyond the issue of the Redeemer's ability to perform a single miraculous action. Even if we grant that either the Redeemer neither has nor lacks omnipotence or that there is no property of omnipotence simpliciter, and we grant that the Redeemer has all his divine properties in an encapsulated way, one would still think that it would have to be true that, with respect to any broad range of action, either the Redeemer could perform those actions or he could not. Now suppose that we are considering the concept (rather than the property) of omnipotence, and suppose our account is in terms of a maximal set of powers any being could possess. Call that set of powers (whatever set it turns out to be) "PG." Now does the Redeemer possess all those powers that comprise PG? If he does, then his range of powers goes far beyond those of standard, limited humans (this is, of course, no surprise). If he does not possess those powers, then one might wonder how he could be even "omnipotent-qua-divine," or at any rate how he could possess enough power for divinity. Similarly, let's call the set of powers possessed by human beings in virtue of their humanity "PH."Now we can ask if the Redeemer's set of powers is significantly greater than PH. If it is significantly greater, then we are again faced with the question of how such a being could legitimately be one of us (particularly when one realizes that this is only one of many key differences between us and the Redeemer; there are similar differences in knowledge, goodness, contingency/necessity, etc.). If it is not, then the Redeemer lacks PG, and the questions about how such a being could be divine pop back up. In short, we find ourselves not substantially better off than we were before the quilmove was employed. So the third way, together with either a denial of the Law of the Excluded Middle for properties or omniproperty nominalism, fails as a means of resolving the logical puzzles of the Incarnation.

\section{Conclusion}

Let's take stock. This essay began with the claim that the Incarnation causes trouble for the doctrine of divine atemporality. We then looked at an objection of sorts to the argument presented; the objection stated that the problem at hand was just one of 
many similar Leibniz's Law problems and that once a solution was found to one, a solution would be found to all. The qua-move was thought to be a model for a solution of the right sort. However, close examination has revealed that the qua-move is unlikely to be helpful as a means of resolving any of our Incarnational difficulties. So we are once again left with the argument that the Incarnation would seem to be inconsistent with timelessness for the Godhead.

Yet it can be objected that if we accept divine temporality, then the very same line of reasoning should convince us that God is also corporeal and spatial. In this essay, I have argued that the traditional Christian can acknowledge that the Redeemer was indeed corporeal and spatial during his earthly ministry, and perhaps from thenceforth, without saying anything terribly unorthodox. For while she cannot consistently say that divinity requires incorporeality and aspatiality, she can claim that these are ceteris paribus properties of divinity. And of course, there are two other divine persons, Partakers in the Triune Life, who are not in any respect corporeal. However, if one holds that Christ no longer has a human body, one can certainly claim that the present-tense proposition "God is corporeal" is false since there is no divine person who has a body.

I am concerned in this essay to argue for only two points. First, it will not do for the advocate of atemporality to dismiss the charge that her view is inconsistent with the orthodox understanding of the Incarnation. For there are ways of handling the standard Leibniz's Law problems that cannot be pressed into service to dispel the apparent inconsistency between the doctrines of timelessness and the Incarnation. The second conclusion is that there is at present some reason to doubt the utility of the qua-move as a means of solving Christological problems. Perhaps there is some way of understanding the property ascription qua natures that can be pressed into service here, but the three clearest possibilities are in the end unhelpful.

Notes

Thanks to Laura Garcia for discussion and to David Woodruff for written comments on an earlier version of this essay.

1. Thomas D. Senor, "Incarnation and Timelessness," Faith and Philosophy, 7, no.2 (April 1990), 149-64

2. Brian Leftow offers an argument similar to this in the introduction to his book Time and Eternity (Ithaca: Cornell University Press, 1990). Leftow credits Eleonore Stump with having suggested it to him. I also heard this argument from Norman Kretzmann in response to a question at the conference "The God Who Acts in History," held at UCLA, March 31, 1990.

3. As we have described them so far, it is not clear whether properties that can be only obcrved via instruments count as observable. I do not think that for our purposes it matters. A long as we have a concept clear enough to be usable in mariy ordinary cases, we have a concept clear enough for our purposes.

4. In this essay, I will write as though the standard theistic attributes of omnipotence, onniscience, omnibenevolence, and the like constitute the kind-essence of divinity. I do have serous reservations about this, but laying them aside will cause no problems here. For a discussion of my reservations, see my article "God, Supernatural Kinds, and the Incarnation," Religious Studies 27 (1992) 353-70.
5. Thomas V. Morris, The Logic of God Incarnate (Ithaca: Cornell University Press, 1986); Richard Swinburne, first in "Could God Become Man?" in The Philosophy in Christianity (Cambridge: Cambridge University Press, 1989), 53-70, then in The Christian God (London: Oxford University Press, 1994)

6. It would, of course, cause yet another Leibniz's Law problem for the Incarnation, for surely no divine being can be depraved.

7. Thanks to Laura Garcia for reminding me of this objection.

8. Now one might think that " $\mathrm{X}$ 's being conceived at $t$ " entails that " $\mathrm{X}$ begins to exist at $t$," and hence that if Jesus were "conceived by the Holy Spirit" we would have a Leibniz's Law problem here (since, being God the Son, Jesus must also be said to be pre-existent and necessarily existent). I am relegating this discussion to a footnote since this is not a case of a conflict between an observable property and alleged divine properties. Nevertheless, I think that the Morris/Swinburne line has an answer here as well, although it is admittedly not as smooth as the answer to the previous problem. One can maintain that conception is the first moment of existence for a typical human (if indeed it is; this is, of course, a very controversial assumption) but that it is not kind-essential for being human. Furthermore, as we have seen, we can distinguish between kind and individual essences and claim that for a standard human being the property of, say, beginning to exist at conception is a part of his or her individual essence.

9. Although "impassibility" has many meanings, I intend to understand "God is impassable" as "God is without an inner emotional life." For a good discussion of the many meanings of "impassable," see Richard E. Creel, Divine Impassibility: An Essay in Philosophical Theology (Cambridge: Cambridge University Press, 1986).

10. One can see that Christ's apparent claim does not entail a lack of omniscience by noting that Christ's being reported to have made that claim does not entail that he actually made it. I am making only a minimal assumption about the way the Christian theologian needs to take biblical data. Note that the problems the Incarnation creates for timelessness and incorporeality depend only on the claim that Jesus Christ, a human being, was God Incarnate; it matters not whether the Gospels' accounts of his life and ministry are generally accurate.

11. Senor, "God, Supernatural Kinds, and the Incarnation."

12. Clearly, one who adopts this view will reject a traditional reading of the attribute of immutability since taking on a nature is a paradigm of intrinsic change.

13. This is precisely the line taken (or at least suggested) by Eleonore Stump and Norman Kretzmann in sec. 5 of their important paper "Eternity," Journal of Philosophy 78 (1981), $429-58$

14. It is not clear whether these sets exhaust all of the Redeemer's properties or whether there is a third set of simpliciter properties. For example, it is not clear whether the property "having knowledge" is an attribute of the Redeemer's or whether the relevant attributes are "having-knowledge-qua-God" or "having-knowledge-qua-man."

15. Recall that the qua-move is made for the purpose of showing how the apparently contradictory properties of, e.g., omnipotence and non-omnipotence, can be had by a single individual. If, however, one is not committed to the truth of sentences like "The Redeemer is ormnipotent" and "The Redeemer is non-omnipotent," then the whole motivation for the qual-move is shot, at least as far as I can see.

16. This is a rather weak account by contemporary (and mediev:1) standards. It is frcquently maintained that to be God involves having the omniproperties essentially. In what follows, I will assume only the weaker understanding of divinity; but it should be noted that any problems that we encounter with the weaker notion and its compossibility with human nature will be at least as significant as what we would encounter with the stronger notion. 